(6) OPEN ACCESS

${ }^{1}$ Aviation Medicine Clinical Service, RAF Centre of Aviation Medicine, RAF Henlow,

Bedfordshire, UK

${ }^{2}$ Aviation Medicine Department, AeMC, Percy Military Hospital, Clamart, France, Clamart, Île-deFrance, France

${ }^{3}$ German Air Force Center for Aerospace Medicine, Fuerstenfeldbruck, Germany ${ }^{4}$ Aeromedical Centre, Swiss Air Force, Dubendorf, Zürich, Switzerland

${ }^{5}$ Aeromedical Consult Service, United States Air Force School of Aerospace Medicine, WrightPAtterson AFB, Ohio, USA

${ }^{6}$ Cardiac Surgery Department, Luzerner Kantonsspital, Luzern, LU, Switzerland

${ }^{7}$ Canadian Forces Environmental Medical Establishment, Toronto, Ontario, Canada ${ }^{8}$ Department of Cardiology, University Medical Center Utrecht and Central Military Hospital, Utrecht, The Netherlands

\section{Correspondence to} Dr Edward D Nicol, Aviation Medicine Clinical Service, RAF Centre of Aviation Medicine, RAF Henlow, Bedfordshire, SG166DN; e.nicol@nhs.net

Received 3 June 2018 Revised 25 July 2018 Accepted 26 July 2018

\title{
Congenital heart disease in aircrew
}

\author{
Edward D Nicol, ${ }^{1}$ Olivier Manen, ${ }^{2}$ Norbert Guettler, ${ }_{7}^{3}$ Dennis Bron, ${ }^{4}$ \\ Eddie D Davenport, ${ }^{5}$ Thomas Syburra, ${ }^{6}$ Gary Gray, ${ }^{7}$ Joanna d'Arcy, ${ }_{1}^{1}$ Rienk Rienks ${ }^{8}$
}

\section{ABSTRACT}

This article focuses ${ }^{i}$ on the broad aviation medicine considerations that are required to optimally manage aircrew ${ }^{\text {ii }}$ with suspected or confirmed congenital heart disease (both pilots and non-pilot aviation professionals). It presents expert consensus opinion and associated recommendations and is part of a series of expert consensus documents covering all aspects of aviation cardiology. This expert opinion was born out of a 3 year collaborative working group between international military aviation cardiologists and aviation medicine specialists, as part of a North Atlantic Treaty Organization (NATO) led initiative to address the occupational ramifications of cardiovascular disease in aircrew (HFM251) many of whom also work with and advise civil aviation authorities.

\section{INTRODUCTION}

Congenital heart disease (CHD) ranges from simple abnormalities, such as isolated bicuspid aortic valve disease, to complex cyanotic heart disease. Advances in corrective, or palliative, surgical techniques and perioperative care in children with CHD have resulted in a significant improvement in mortality. ${ }^{1}$ It is estimated that $0.3-0.5 \%$ of the adult population live with adult $\mathrm{CHD}(\mathrm{ACHD})^{2}$ and applications for aviation medical certification now include individuals who have an almost normal quality of life despite their underlying congenital disease. Some CHD conditions may present in those already undertaking flying duties and it is necessary to be able to appropriately risk assess CHD and give appropriate clinical and occupational advice when considering actual or potential aircrew duties.

It should be noted, however, that individuals with ACHD are known to have higher rates of arrhythmia, chest pain, hospitalisation and emergency department attendance than the general population. $^{3} 4$ Additionally, most individuals require long-term follow-up due to the risk of longterm sequelae and the need for intervention and surgery, while the aviation environment may expose aircrew to additional physiological stressors (such as hypoxia, hypobaria and potentially sustained acceleration $\left(+G_{\mathrm{z}}\right)$ ) that may increase these risks further. $^{5-7}$ Therefore, appropriate risk assessment is paramount to ensure flight safety.

This article outlines the most common conditions likely to be encountered by those assessing, or advising, on suitability for aircrew duties in those individuals with known CHD. The spectrum of CHD is such that clinical manifestations of any given diagnosis are highly variable, and the surgical and interventional procedures performed in any given condition may also be different and multiple. It is therefore essential that individuals are comprehensively assessed on a case-by-case basis, and access to complete surgical, interventional, diagnostic imaging and prior investigations is paramount to making an informed decision on suitability to fly.

\section{RISK ASSESSMENT IN AIRCREW}

As with all cardiovascular conditions in aircrew, the aeromedical risk assessment extends well beyond the usual clinical risk assessment. The aeromedical significance versus clinical significance of any CHD diagnosis will be determined by the potential physiological consequences of the underlying pathology in the aviation environment. Valvular stenosis, regurgitation, shunts and coronary anomalies of modest concern clinically may be aggravated by the stressors of flight with an accompanying increase in aeromedical risk. ${ }^{6}$

${ }^{\mathrm{i}}$ Evidence-based cardiovascular risk assessment in aircrew poses significant challenges in the aviation environment as data to support decision making at the low level of tolerable risk in aviation are rarely available from the published literature. As a result, there are discrepancies between aviation authorities' recommendations in different countries, and even between licensing organisations within single countries. The North Atlantic Treaty Organization (NATO) Human Factors in Medicine (HFM) - 251 Occupational Cardiology in Military Aircrew working group comprises full-time aviation medicine and aviation cardiology experts who advise both their military and civil aviation organisations including, but not limited to, the US Federal Aviation Authority (FAA), UK Civil Aviation Authority (CAA), European Aviation Safety Agency (EASA) and North American Space Agency (NASA). The recommendations of this group are a result of a 3 year working group that considered best clinical cardiovascular practice guidelines within the context of aviation medicine and risk principles. This work was conducted independently of existing national and transnational regulators, both military and civilian, but considered all available policies, in an attempt to determine best evidence-based practice in this field. The recommendations presented in this document, and associated articles, is based on expert consensus opinion of the NATO group. This body of work has been produced to develop the evidence base for military aviation cardiology and to continue to update the relevant civilian aviation cardiology advice following the 1998 European Society of Cardiology aviation cardiology meeting.

To cite: Nicol ED, Manen 0 Guettler N, et al. Heart 2019;105:s64-s69. 
Simple CHD, especially if repaired in childhood, may be acceptable, and allow either full or restricted aircrew duties to be undertaken. Aeromedical risk assessment is also dependent on aircrew role and the aircraft type duties are undertaken on, with appropriate subsequent risk assessment based on these factors. ${ }^{8}$ Conditions that require routine and regular cardioincrease the risk of aeromedically important sequalae (such as palpitations and chest pain) are unlikely to be compatible with unrestricted professional aircrew duties and, due to the significant economic investment in aircrew applicants, may preclude individuals from successfully applying to fly. In the military, additional considerations, such as the risk of endocarditis to either native cardiac defects or surgical interventions, may also affect the assessment of suitability for both aircrew candidates

It is possible to return to flying after a diagnosis of CHD, although often in a limited occupational role, and to non-high-performance airframes that place less physiological strain on the heart. Restrictions on aircrew licences often apply following cardiovascular intervention and initial investigation and follow-up usually requires intensive additional tests at specific time points.

\section{APPROACH TO INVESTIGATING CHD IN AIRCREW}

Aircrew with a suspected diagnosis of CHD usually require extensive examinations and may require restriction or grounding while these are undertaken. Investigation is often extensive and time consuming and aircrew should be counselled accordingly.

Routine aircrew examinations should include a thorough medical history including a detailed family history, a physical examination, and 12-lead ECG. Many native or corrected CHD diagnoses are associated with abnormal ECG findings and these may mandate further investigation and lead to restriction, or withdrawal, of flying privileges.

\section{First level investigation}

Further investigation in any individual with suspected CHD should include echocardiography, Holter monitoring (24 hours to 7 day), and exercise ECG (see table 1 for recommendations). If hypertension is suspected, such as in coarctation assessment, 24-hour ambulatory blood pressure measurement should be included.

\section{Second level investigation}

In many instances of suspected or known CHD, cardiac MRI (CMR), cardiovascular CT or invasive coronary angiography will be indicated. In addition to the investigation to fully elucimay be required that are specific to myocardial, valvular, coronary or electrophysiological disease. ${ }^{679}$ vascular follow-up, have residual physiological consequence, or and existing aircrew. date the breadth and complexity of $\mathrm{CHD}$, other investigations

Table 1 Investigation of suspected congenital heart disease (CHD)

\begin{tabular}{ll}
\hline $\begin{array}{l}\text { Aircrew with suspected CHD should be investigated with } \\
\text { echocardiography, Holter monitoring and exercise ECG }\end{array}$ & $\begin{array}{l}\text { Strongly } \\
\text { recommended } \\
\text { Strongly } \\
\text { Aircrew with a suspected diagnosis of CHD usually require } \\
\text { extensive examinations and may require restriction or grounding } \\
\text { while these are undertaken }\end{array}$ \\
$\begin{array}{l}\text { In those with a confirmed congenital abnormality, further } \\
\text { recommended }\end{array}$ & Recommended \\
$\begin{array}{l}\text { a specialist in CHD. This may require cardiac MRI (CMR), } \\
\text { cardiovascular CT or invasive cardiac catheterisation. Other } \\
\text { investigations may be required that are specific to myocardial, } \\
\text { valvular, coronary or electrophysiological disease }\end{array}$ & \\
\hline
\end{tabular}

\section{SIMPLE CONGENITAL DEFECTS Coronary artery anomalies}

The prevalence of aberrant coronary anatomy is reported at around $1 \%$ in the general population ${ }^{3}$; however, the true incidence may well be greater, as CT coronary angiography (CTCA) identifies as many as double those seen on invasive coronary angiography (ICA). ${ }^{10}$ This is important as CTCA becomes a more established technique in the assessment of suspected coronary artery disease in aircrew. ${ }^{11}$ Most anomalous coronary arteries represent clinically non-significant variations of 'normal' coronary anatomy; however, a small number of individuals have clinically important aberrant anatomy that may impair coronary blood flow on exercise and have relevant aeromedical ramifications. ${ }^{12}$ The identification of aberrant coronary anatomy should lead to active exclusion or confirmation of concomitant CHD. ${ }^{13} 14$

While most anomalous coronary variants are compatible with unrestricted flying duties, aircrew with flow-limiting anomalies may need to be restricted or even permanently disqualified (see table 2 for recommendations). Retro-aortic and pre-pulmonary anomalous coronary anatomy confer a better prognostic outcome than so called 'malignant' inter-arterial variants. This evidence comes from autopsy studies of young people who have suffered a sudden cardiac death. High-risk coronary anatomy variants include single coronary arteries, coronary atresia, those that are thought to be intramural (passing within the aortic wall) and those passing between the right ventricular outflow tract and aortic root. These morphologies, and any others associated with symptoms, all require careful additional assessment. Negative perfusion imaging and acceptable postoperative investigations following any surgical intervention ${ }^{15}$ are required before a return to any flying duties can be considered.

\section{Table 2 Coronary artery anomalies}

\begin{tabular}{ll}
\hline Aircrew or applicants with a suspected diagnosis of a clinically & Strongly \\
significant coronary artery anomaly usually require restriction or & recommended \\
grounding while investigation is undertaken & \\
Negative perfusion imaging, acceptable investigations following & Strongly \\
any surgical intervention, and a cardiac risk within acceptable & recommended \\
limits for role, are required before a return to any flying duties can \\
be considered
\end{tabular}

\footnotetext{
${ }^{i i}$ Aircrew are defined somewhat differently in civil and military aviation. NATO and the International Civil Aviation Organization (ICAO) delegate the definition of aircrew to national authorities. In the civilian sector aircrew are often categorised as flight crew (pilots)/technical crew members and cabin crew, with separate regulation for air traffic controllers (ATCO). The military define aircrew more broadly as 'persons having duties concerned with the flying or operation of the air system, or with passengers or cargo when in flight'. From a risk perspective, professional (commercial) pilots have a higher attributable risk than private pilots and non-pilot aircrew. Controllers are considered to have an attributable risk equivalent to professional pilots. From a cardiovascular perspective, aircrew whose flying role includes repetitive exposure to high acceleration forces $\left(G_{z}\right)$ comprise a subgroup who, due to the unique physiological stressors of this flight environment, often require specific aeromedical recommendations. A more detailed description of aircrew is available in table 1 of the accompanying introductory paper on aviation cardiology (Nicol ED, et al. Heart 2018;105:s3-s8. doi:10.1136/heartjnl-2018-313019).
} 


\section{Congenital valve disease}

Full details of valve assessment are beyond the scope of this manuscript but described in detail in the accompanying paper on valve disease in aircrew. ${ }^{6}$ As a rule, mild or worse stenosis and moderate or worse regurgitation are likely to lead to flying restrictions.

\section{Bicuspid aortic valve disease and coarctation}

Bicuspid aortic valve (BAV) disease is the the most common form of CHD with a prevalence of approximately $1 \% \cdot{ }^{16}$ It is often asymptomatic in childhood and found incidentally in adulthood-that is, a systolic murmur found in aircrew undergoing a periodic medical examination (PME). Importantly BAV disease is associated with dilatation of the ascending aorta and aortic coarctation, and both should be actively excluded in aircrew. Supra- and sub-aortic stenosis are often associated more complex CHD, which in themselves are likely to be disqualifying.

Congenital BAV encompasses a wide spectrum of pathology. The development and rate of progression of stenosis, regurgitation and aortopathy associated with BAV is variable so that trained aircrew with BAV will require periodic follow-up more than is generally recommended clinically (see table 3 for recommendations). The lack of individual predictability of BAV disease progression, potential risks associated with the aviation environment (particularly with sustained $+\mathrm{G}_{\mathrm{z}}$ acceleration) and the associated risk of endocarditis means that many military employers would not recruit aircrew with known BAV disease. For those with an aortopathy, surgical intervention may be required if the ascending aorta is dilated, ${ }^{6}$ and treatments such as $\beta$-blockers, with their potential impact on $\mathrm{G}_{\mathrm{z}}$ tolerance, may result in restriction or grounding of certain aircrew. ${ }^{5}$

\begin{tabular}{ll}
\hline Table 3 Bicuspid aortic valve disease (BAV) & \\
\hline Trained aircrew found to have BAV require regular periodic & Strongly \\
echocardiographic follow-up. Valve disease should be managed in & recommended \\
accordance with the level of valve dysfunction. & A flying restriction \\
from high-G aircraft (fighter and aerobatic) may be required & \\
Aircrew applicants with known BAV disease will require career- & Consider \\
long periodic follow-up. This may make them ineligible for military & \\
training on economic grounds & \\
\hline
\end{tabular}

In aircrew with coarctation of the aorta, unrestricted flying may be considered if the defect was surgically corrected in their early teenage years, if the individuals are normotensive, and if regular follow-up with cardiac MRI has been performed and demonstrates no re-coarctation or aneurysm formation. ${ }^{17}$ Concomitant dilation of the ascending aorta with coarctation is usually disqualifying. In those with confirmed coarctation of the aorta, high-performance flying is usually not possible due to a lack of data concerning the possible development of complications caused by $+\mathrm{G}_{\mathrm{z}}$ acceleration.

\section{Pulmonary stenosis}

Pulmonary stenosis (PS) may occur in isolation or as part of a wider constellation of defects (such as tetralogy of Fallot). It occurs in $10 \%$ of all cases of CHD and while usually valvular in nature, it may also affect the right ventricular infundibulum and supra-valvular pulmonary artery. As with BAV there is a spectrum of disease; severe disease is mostly intervened on in childhood, usually with balloon valvuloplasty. Sub- and supra-valvular PS is usually incompatible with aircrew licensing; the former is usually associated with additional CHD and the latter with multiple stenoses throughout the entire pulmonary tree. Progression of more mild forms of disease is not uncommon. However, aircrew may remain asymptomatic, even with significant disease, with a systolic murmur the most common finding that declares this at aircrew PME.

There is an associated risk of atrial arrhythmia, secondary to right atrial dilation, in PS, as well as an additional endocarditis risk. For these reasons military applicants are often declined; however, depending on the severity of disease, licensing may be possible with civilian commercial organisations. For trained aircrew with disease, ongoing certification is dependent on disease severity and, after exclusion of additional CHD, decisions based on the same criteria as acquired disease. ${ }^{6}$ Pulmonary valve replacement, either surgically or with percutaneous intervention, is usually incompatible with ongoing flying due to the recurrence rate of both PS and pulmonary regurgitation (see table 4 for recommendations). ${ }^{18}$

\section{Table 4 Pulmonary valve disease}

Aircrew with mild pulmonary stenosis (PS) should be considered unfit for high performance flying, and unfit solo flying. Those with moderate or severe PS should be considered unfit for flying duties Pulmonary valve replacement, either surgically or with percutaneous intervention, is usually incompatible with ongoing flying

\section{Patent ductus arteriosus}

Patent ductus arteriosus (PDA) is usually recognised early in life and closed pharmacologically (with ibuprofen or indomethacin), with surgical ligation or a percutaneous closure device. PDA can be associated with BAV, subaortic stenosis, PS, and aortic root disease, and these must be excluded before PDA closure is performed. Occasionally, PDAs that have been closed early in childhood, recanalise as the individual grows. In adulthood, further recanalisation is unlikely. If closed in childhood, with appropriate follow-up, a closed PDA is compatible with unrestricted flying. If a percutaneous device closure has been used, then this may preclude aircrew from high-performance flying due to concerns regarding device movement or embolisation. Additionally, the risk of endocarditis may preclude military service.

If the PDA is small and untreated, abnormal physiology is rarely seen in adults. It is rarely associated with an increased risk of endocarditis and may result rarely in pulmonary hypertension, sometimes developing slowly over many years. This may manifest in aircrew as palpitations secondary to right atrial dilation, dyspnoea on exertion, or hypoxia. Pulmonary hypertension is a bar to initial flying certification and is usually associated with restriction of flying privileges, or grounding, if diagnosed in existing aircrew.

\section{Patent foramen ovale and atrial septal defects}

Patent foramen ovale (PFO) is present in $25-33 \%$ of the population. It is often an incidental finding in asymptomatic aircrew undergoing echocardiography for investigation of other suspected cardiac disease. Unless associated with an embolic event or decompression illness (DCI) it should be regarded as a normal variant. Concern is often expressed regarding increased shunts associated with Valsalva-like straining manoeuvres in certain aircrew (such as the anti $+G_{z}$ straining manoeuvre to counter the effects of sustained acceleration in aerobatics or high-performance military 
aircraft) and positive pressure breathing; however, there is no evidence that suggests an increased risk in this cohort.

In individuals with a confirmed cerebrovascular event (CVE), where a PFO is potentially implicated in the aetiology, management may include antiplatelet therapy, anticoagulation therapy and/or device closure. ${ }^{19}$ It is generally a safe procedure usually requiring post-interventional antiplatelet therapy for at least 6 months; however, clinical practice is variable between cardiologists and neurologists. ${ }^{20}$

Following any event, either CVE or DCI, aircrew should be grounded, investigated and treated (see table 5 for recommendations). Return to limited aircrew duties is often possible, depending on the type of aircraft operated and the aircrew role performed. Neurological evaluation is mandatory for aeromedical assessment in these patients and for mostly determining future flying career. Device closure is managed as with atrial septal defect (ASD) cases.

\begin{tabular}{|c|c|}
\hline $\begin{array}{l}\text { Unless associated with an embolic event or decompression illness } \\
\text { (DCI), a PFO should be regarded as a normal variant in aircrew }\end{array}$ & $\begin{array}{l}\text { Strongly } \\
\text { recommended }\end{array}$ \\
\hline $\begin{array}{l}\text { Aircrew with an untreated ASD should be grounded, while } \\
\text { investigated and treated }\end{array}$ & $\begin{array}{l}\text { Strongly } \\
\text { recommended }\end{array}$ \\
\hline $\begin{array}{l}\text { Following either a cerebrovascular event (CVE) or DCI, aircrew } \\
\text { should be grounded, investigated for PFO and treated as } \\
\text { required. Return to limited aircrew duties is often possible } \\
\text { following PFO closure, pending satisfactory neurological } \\
\text { assessment. It is recommended that pilot aircrew be restricted to } \\
\text { dual crew operations and all aircrew to low performance aircraft }\end{array}$ & Recommended \\
\hline $\begin{array}{l}\text { While ASD closure (either surgical or percutaneous) may allow a } \\
\text { return to flying duties, it is recommended that this is restricted } \\
\text { to dual operator, low performance and non-flight-critical aircrew } \\
\text { roles }\end{array}$ & Recommended \\
\hline
\end{tabular}

Nearly all large ASDs are now detected and closed in childhood, either with percutaneous closure devices or, if not suited to these devices, surgically. However, ASD may remain undiagnosed until adulthood. ASDs may occur in isolation or as part of a wider constellation of CHD. Isolated ASDs may be asymptomatic before early adulthood, and are often detected incidentally in aircrew at their PME, with an abnormal ECG or an ejection systolic murmur. Unless closed early in adulthood, all ASDs are associated with atrial arrhythmias, particularly atrial flutter and atrial fibrillation (AF), with a peak in prevalence in the fourth decade. Indications for closure are significant shunts (Qp:Qs >2), regardless of symptoms, and suspicion of paradoxical embolism. Ostium primum defects are rare and may affect mitral valve function; they are not suitable for device closure. Ostium primum ASD may be the atrial component of an atrioventricular septal defect (AVSD). In AVSD, there is no mitral valve, but a common atrioventricular (AV) orifice with a common AV valve. AVSD should be dealt with in the same way as other complex CHDs.

In adults, device closure has become the therapy of choice, especially for secundum defects. ${ }^{21}$ As with those with a clinically significant PFO, device closure is usually followed by antiplatelet therapy for at least 6 months. ${ }^{22}$ In non-aircrew, small post-intervention shunts do not usually require further intervention and are usually haemodynamically benign. However, these do require further assessment in aircrew, especially if their occupational role requires positive pressure breathing. Long-term data to support aeromedical disposition post PFO and ASD intervention are lacking, and while percutaneous devices re-endothelialise over approximately 4-6 months, there may be a small increased risk of endocarditis and arrhythmia associated with these devices. ${ }^{23}$ There has also been concern regarding erosion of devices, ${ }^{24}$ and although rare, this, and the other potential long-term sequalae reported, may exclude single operator, high performance or flight critical aircrew roles in individuals with previous intervention, either percutaneous or surgical. Significant arrhythmia risk must be excluded before certification and, if deemed initially acceptable, must be followed up closely with at least annual Holter and echocardiographic monitoring.

\section{Ventricular septal defect}

Isolated ventricular septal defect (VSD) accounts for about a third of simple CHD. ${ }^{21}$ There is a spectrum of disease, both related to size and location. VSD are most commonly peri-membranous (80\%). Small, restrictive VDS (Qp:Qs ratio <1.5) may cause a palpable thrill and loud pansystolic murmur. About 50\% of small VSDs close spontaneously by adulthood and those that do not are rarely considered for surgical intervention. While of limited physiological significance they are associated with an increased risk of endocarditis and may preclude entry into the military. If found incidentally in trained military aircrew, flying restrictions are usually not required, while in the civil sector, these defects are often compatible with unrestricted aircrew roles (see table 6 for recommendations).

\begin{tabular}{|c|c|}
\hline $\begin{array}{l}\text { Small, physiologically mild (Qp:Qs<1.5) VSD are usually } \\
\text { compatible with unrestricted flying duties, but may be a bar to } \\
\text { military aircrew applicants }\end{array}$ & Recommended \\
\hline $\begin{array}{l}\text { VSDs requiring surgery are usually a bar to aircrew applicants } \\
\text { and often result in grounding or restrictions in trained aircrew. It } \\
\text { is recommended that post surgery, aircrew are restricted to dual } \\
\text { operator, low performance and non-flight-critical aircrew roles }\end{array}$ & Recommended \\
\hline
\end{tabular}

By contrast, large, unrestrictive VSDs (QP:Qs >2) are associated with significant haemodynamic sequalae, such as pulmonary hypertension, unless closed early, either surgically or percutaneously. If VSD closure is indicated, surgical repair is usually the procedure of choice. Transcatheter closure is an alternative in patients with increased risk factors for surgery, after multiple previous cardiac surgical interventions, or if the VSD is poorly accessible for surgical closure. ${ }^{2125}$

Surgical intervention in childhood is associated with a near normal life expectancy but is associated with both an increased incidence of arrhythmias (especially AV conduction defects) and aortic regurgitation. For these reasons, professional aircrew applicants may not meet the selection standards. Incomplete closure, with small residual leaks, are not uncommon post-VSD intervention, and usually do not require additional intervention in those living and working at sea level. However, in aircrew, these do require further assessment, especially if their occupational role requires positive pressure breathing.

\section{Marfan syndrome}

Marfan syndrome encompasses a spectrum of disease including cardiac, ophthalmic, musculoskeletal and systemic manifestations. Not all Marfan patients have the whole myriad of systemic presentation and aircrew with Marfan syndrome may be identified following the detection of a cardiac murmur (usually associated with aortic or mitral regurgitation). Some aircrew may 
have Marfan features but do not meet the full criteria for Marfan syndrome.

Marfan syndrome is associated with dilatation of the aortic root and ascending aorta with effacement of the sinotubular junction. Full assessment of the thoracic aorta is required, and, if normal, restricted flying certification in existing aircrew may be appropriate if no disbarring ocular or systemic manifestations are present. Aortic dilation in aircrew with Marfan syndrome usually results in individuals being deemed unfit to fly, due to the risk of dissection and aortic rupture. Those with aortic pathology should be referred to a cardiologist with expertise in aortopathy. Aircrew who have had surgery are at ongoing risk of dissection, both proximal and distal to the repair, and progressive valvular regurgitation and remain unfit to fly. Due to the systemic nature of the syndrome and the likelihood of aortic dilation, aircrew applicants are unlikely to meet selection criteria (see table 7 for recommendations).

\begin{tabular}{lll}
\hline Table 7 & Marfan syndrome & \\
\hline Aircrew with suspected Marfan syndrome should be grounded & $\begin{array}{l}\text { Strongly } \\
\text { and thoroughly investigated for cardiac and systemic disease } \\
\text { recommended }\end{array}$ \\
In aircrew with confirmed Marfan syndrome with no significant & Recommended \\
aortic dilatation, ocular or systemic manifestations, return to & \\
restricted, dual operator, low performance, and non-flight-critical & \\
aircrew roles may be possible, with at least annual follow-up & \\
\hline
\end{tabular}

\section{Ebstein's anomaly}

Ebstein's anomaly is a moderately complex congenital heart defect in which the tricuspid valve leaflets are displaced towards the apex of the right ventricle. This results in 'atrialisation' of a portion of the morphologic right ventricle which is contiguous with the right atrium. This causes the right atrium to be large and the anatomic right ventricle to be small. It is an uncommon finding in aircrew but may manifest itself as palpitations secondary to an AV re-entry tachycardia, AF or atrial flutter. Over $50 \%$ of individuals with Ebstein's anomaly have an associated shunt between the right and left atria, either an ASD or a PFO. It is rarely an incidental finding, and, if so, requires appropriate investigation to exclude additional CHD and electrophysiological abnormalities. Restriction to flying privileges may be required.

\section{COMPLEX CHD}

Complex CHD is almost always incompatible with aircrew licensing and often associated with significant physiological impairment and reduced life expectancy (see table 8 for recommendations). The only exception to this is tetralogy of Fallot, where surgical intervention has resulted in near normal life expectancy. ${ }^{26}$ However, even in mild forms of the disease, individuals with tetralogy of Fallot require life-long follow-up and are at increased risk of valvular dysfunction and arrhythmia. ${ }^{27}$ Current civil regulations allow unrestricted flying if the individual has been operated on before the age of 12 years, provided regular cardiological evaluation does not reveal any evidence of residual right ventricular hypertrophy, pulmonary regurgitation or ventricular arrhythmia. However, a multi-pilot restriction would seem more sensible given the increased aeromedical risk. In military applicants, tetralogy of Fallot, even after surgery, is disqualifying for flying.

Table 8 Complex CHD

Complex CHD is incompatible with military aircrew duties

Tetralogy of Fallot may be acceptable for civilian aircrew duties; however, it is recommended to restrict to multi-pilot operations

\section{CONCLUSION}

Assessment of aircrew with CHD mandates a detailed assessment, with access to as complete a medical record as possible. The decision with regards to aircrew employability, in those with $\mathrm{CHD}$, requires an understanding of potential or current occupational roles, the environmental physiology and a specific risk assessment. As a general principle, simple $\mathrm{CHD}$, especially if repaired in childhood, may be acceptable, and allow either full or restricted aircrew duties to be undertaken. Despite this, arrhythmia, chest pain and endocarditis risk are all elevated in many individuals and remain significant concerns in aircrew; case-by-case assessment is required in all cases, often in conjunction with a CHD specialist.

Contributors All authors are members of the HFM-251 panel and contributed to the writing of this manuscript.

Funding Produced with support from NATO CSO and HFM-251 Partner Nations. Competing interests None declared.

Patient consent Not required.

Provenance and peer review Not commissioned; externally peer reviewed.

Open access This is an open access article distributed in accordance with the Creative Commons Attribution Non Commercial (CC BY-NC 4.0) license, which permits others to distribute, remix, adapt, build upon this work non-commercially, and license their derivative works on different terms, provided the original work is properly cited, appropriate credit is given, any changes made indicated, and the use is non-commercial. See: http://creativecommons.org/licenses/by-nc/4.0/.

\section{REFERENCES}

1 Moller JH, Taubert KA, Allen HD, et al. A special writing group from the task force on children and youth, American Heart Association: cardiovascular health and disease in children: current status. Circulation 1994;89:923-30.

2 Warnes CA, Liberthson R, Danielson GK, et al. Task force 1: the changing profile of congenital heart disease in adult life. J Am Coll Cardiol 2001;37:1170-5.

3 Yamanaka 0, Hobbs RE. Coronary artery anomalies in 126,595 patients undergoing coronary arteriography. Cathet Cardiovasc Diagn 1990;21:28-40.

4 Goktekin O, Dimopolous K, Vatankalu MA, et al. Prevalence of coronary artery disease and relation to chest pain in patients with congenital heart disease. Eur Heart $J$ 2006;27.404.

5 Nicol ED, Rienks R, Gray G, et al. An introduction to aviation cardiology. Heart 2018. TBD.

6 Elefteriades JA. Natural history of thoracic aortic aneurysms: indications for surgery, and surgical versus nonsurgical risks. Ann Thorac Surg 2002;74:S1877-S1880.

7 Guettler N, Bron D, Manen O, et al. The management of cardiac conduction abnormalities and arrhythmia in aircrew. Heart 2018. TBD.

8 Gray G, Rienks R, Davenport ED, et al. Assessing aeromedical risk: a three-dimensional risk matrix approach. Heart 2018. TBD.

9 Davenport ED, Gray G, Rienks R, et al. The management of established coronary artery disease in aircrew without myocardial infarction or revascularization. Heart 2018:TBD

10 Nicol E, Gatzoulis M, Padley SPG, et al. Assessment of adult congenital heart disease with 64-MDCT - beyond coronary lumenography. Clin Radiol 2007;62:518-27.

11 Parsons I, Pavitt C, Chamley R, et al. CT Coronary angiography vs. coronary artery calcium scoring for the occupational assessment of military aircrew. Aerosp Med Hum Perform 2017;88:76-81.

12 Banerjee D, Sriharan M, Nicol E. Malignant anomalous left coronary artery associated with acute coronary syndrome. Cardiol Young 2013;23:149-53.

13 Kim SY, Seo JB, Do KH, et al. Coronary artery anomalies: classification and ECGgated multi-detector row CT findings with angiographic correlation. Radiographics 2006:26:317-33.

14 Nicol ED, Lyne J, Rubens MB, et al. Left main coronary atresia: a more commonly identified condition after the advent of 64-slice CT coronary angiography? J NuCl Cardiol 2007; 14:715-8.

15 Guettler N, Nicol ED, D'Arcy JL, et al. Non-coronary cardiac surgery and interventional cardiology procedures in aircrew. Heart 2018. TBD.

16 Roger VL, Go AS, Lloyd-Jones DM, et al. Heart disease and stroke statistics-2012 update: a report from the American Heart Association. Circulation 2012;125:e2-e220.

17 Joint Aviation Authorities JAA. Manual of Civil Aviation Medicine. Colorado, USA: Global Engineering Documents, 2009

18 Steinberg ZL, Jones TK, Verrier E, et al. Early outcomes in patients undergoing transcatheter versus surgical pulmonary valve replacement Heart. 2017;103: 1455-60. 
19 Carroll JD, Saver JL, Thaler DE, et al. for the RESPECT Investigators. Closure of patent foramen ovale versus medical therapy after cryptogenic stroke. $N$ Engl I Med 2013;368:1092-100.

20 Von Klemperer K, Pavitt C, Uebing A, et al. A National Survey on PFO Device Closure for Cerebral Vascular Events. Open Heart, 2017;4:e000636.

21 Baumgartner H, Bonhoeffer P, De Groot NMS, et al. ESC guidelines for the management of grown-up congenital heart disease (new version 2010). The task force on the management of grown-up congenital heart disease of the European Society of Cardiology (ESC). Eur Heart J 2010;31:2915-57.

22 Masura J, Gavora P, Podnar T. Long-term outcome of transcatheter secundum-type atrial septal defect closure using Amplatzer septal occluders. J Am Coll Cardiol 2005;45:505-7.
23 Mojadidi MK, Zaman MO, Elgendy IY, et al. Cryptogenic stroke and patent foramen ovale. J Am Coll Cardiol 2018;71:1035-43.

24 McElhinney DB, Quartermain MD, Kenny D, et al. Relative risk factors for cardiac erosion following transcatheter closure of atrial septal defects: a case-control study. Circulation 2016;133:1738-46.

25 Butera G, Carminati M, Chessa M, et al. Transcatheter closure of perimembranous ventricular septal defects: early and long-term results. J Am Coll Cardiol 2007:50:1189-95.

26 Murphy JG, Gersh BJ, Mair DD, et al. Long-term outcome in patients undergoing surgical repair of tetralogy of Fallot. N Engl J Med 1993:329:593-9.

27 Gatzoulis MA, Balaji S, Webber SA, et al. Risk factors for arrhythmia and sudden cardiac death late after repair of tetralogy of Fallot: a multicentre study. Lancet 2000;356:975-81. 